\title{
Venècia i la memòria involuntària. Henri de Régnier precursor de Marcel Proust
}

\author{
Antoni MARTí MONTERDE \\ Universitat de Barcelona \\ Grup de Recerca Literatura en l'Espai Intel·lectual Europeu \\ antonimartimonterde@ub.edu
}

\begin{abstract}
RESUM
L'objectiu d'aquest article és rellegir la idea de memòria involuntària de Marcel Proust prenent en consideració un dels precedents literaris que la va fer possible, els relats i esbossos venecians d'Henri de Régnier. La relectura dels passatges sobre Venècia d'Albertine disparue en relació amb la manera de narrar el somieig i la memòria en l'autor dels Esquisses vénitiennes permet subratllar la importància de l'obra d'aquest en el desenllaç de À la recherche du temps perdu, i, en definitiva, amb el conjunt de la concepció proustiana de l'escriptura.
\end{abstract}

Mots claus: Marcel Proust, Henri de Régnier, John Ruskin, memòria involuntària, intertextualitat, Venècia, literatura francesa (s. XX).

[Recibido, octubre 2013; aprobado, septiembre 2014]

Venice and involuntary memory. Henri de Regnier forerunner of Marcel Proust

\begin{abstract}
The aim of this article is to reread the idea of involuntary memory of Proust considering one of the literary wealth that made possible the stories and sketches of Venetian Henri de Regnier. Rereading passages about Venice Albertine disparue regarding the way of narrating the dream and memory allows the author of Esquisses vénitiennes stressed the importance of the work that the outcome of À la recherche du temps perdu, and in defined-going, the whole concept of Proustian writing.
\end{abstract}

Keywords: Marcel Proust, Henri de Régnier, John Ruskin, involuntary memory, intertextuality, Venècia, French literature (s. XX). 
En les darreres pàgines de À la recherche du temps perdu, quan el narrador arriba al palau dels Guermantes i, entotsolat, no s'adona de l'entrada d'un cotxe que l'obliga a retrocedir, tot fent un moviment estrany que el fa trepitjar dues llambordes mal encaixades, esclata el que es considera el centre d'aquella immensa novel·la; és a dir, el desvelament definitiu de la memòria involuntària $i$, amb ella, el desplegament del sentit últim dels centenars de pàgines que el lector de Marcel Proust acabava de girar per retrobar-se al principi del relat:

\begin{abstract}
Je reculai assez pour buter malgré moi contre les pavés assez mal équarris derrière lesquels était une remise. Mais au moment où, me remettant d'aplomb, je posai mon pied sur un pavé qui était un peu moins élevé que le précédent, tout mon découragement s'évanouit devant la même félicité qu'à diverses époques de ma vie m'avaient donnée la vue d'arbres que j'avais cru reconnaître dans une promenade en voiture autour de Balbec, la vue des clochers de Martinville, la saveur d'une madeleine trempée dans une infusion, tant d'autres sensations dont j'ai parlé (...). Comme au moment où je goûtais la madeleine, toute inquiétude sur l'avenir, toute doute intellectuel étaient dissipés. (Proust, 1989: 445)
\end{abstract}

Com és sabut, aquell desequilibri en el terra, en el raonament del narrador, acabarà per posar en relació dos indrets que, en principi, ben poc tindrien en comú, i que es retroben en un tercer amb aquell moviment: Combray i Venècia. Però, mentre podia esperar-se que Combray reaparegués en la novel·la amb la importància amb què en efecte ho fa, resulta menys evident la reaparició de Venècia, certament ineludible; ara bé: ni tan sols la multitud de passatges — breus, sovint el·líptics — que apunten la necessitat d'anar-hi esparsos al llarg els volums anteriors al que recull el viatge del protagonista a la ciutat italiana fan pensar en una reaparició com la que es dóna tantes pàgines després d'haver-la abandonat. En què s'assemblen Combray i Venècia? En la construcció d'una semblança que viu oculta a dins mateix del relat proustià, i que aquell sobtat desequilibri fa emergir:

\begin{abstract}
Et presque tout de suite je la reconnus, c'était Venise, dont mes efforts pour la décrire et les prétendus instantanés pris par ma mémoire ne m'avaient jamais rien dit et que la sensation que j'avais ressentie jadis sur deux dalles inégales du baptistère de Saint-Marc m'avait rendue avec toutes les autres sensations jointes de ce jour-là à cette sensation-là, et qui étaient restées dans l'attente, à leur rang, d'où un brusque hasard les avait impérieusement fait sortir, dans la série des jours oubliés. De même le goût de la petite madeleine m'avait rappelé Combray. Mais pourquoi les images de Combray et de Venise m'avaient-elles à l'un et l'autre moment donné une joie pareille à une certitude et suffisante sans autres preuves à me rendre la mort indifférente? (Proust, 1989: 446)
\end{abstract}

Que, al capdavall, Combray, l'indret on comença el relat, torni a tenir un paper fonamental en l'argumentació del narrador resultava, si no previsible - considerar-ho així seria redundant: tot és previsible en aquesta novel·la, però d'una altra manera-, coherent. Però, el lloc atorgat a Venècia en aquest raonament, i la manera com es posen de costat una ciutat com la italiana i un indret que, no per imaginari, resulta impossible no considerar-lo real en les seves ficcionalitzacions referencials ${ }^{1}$, ha de resultar necessàriament intrigant.

L'explicació la trobem alguns centenars de pagines abans, en el capítol III de Albertine disparue, que algunes edicions titulen «Estada a Venècia». La primera publicació d'aquell capítol, sota el títol «À Venise», s'havia fet en una revista, Feuillets d'art, en 1919, de

\footnotetext{
${ }^{1}$ Sobretot si acceptem la decisió municipal de la vila d'Illiers de canviar el seu topònim que actualment és IlliersCombray. La irrealitat real de Combray, amb aquella decisió, passava a ser simètrica a la realitat irreal de Venècia.
} 
manera independent. És important remarcar el fet que hi ha diverses edicions i versions d'aquest capítol perquè entre la primera edició en forma de llibre -i les successives edicions que en prenien aquell estat del text com a lliçó- i la que es considera actualment com a edició definitiva - la segona dins la Pléiade - hi ha força variants, i hi son freqüents els afegitons i les supressions, fins el punt que es considera aquest volum el més difícil d'establir i el més polèmic en els seus detalls. Aquestes variants afecten precisament mitja dotzena de pàgines clau per a entendre aquest vincle entre Combray i Venècia, que els quaderns d'esborranys i de textos passats a net per l'autor ha permès clarificar. (Yoshida, 1987; Milly, 1994) El fragment en qüestió, un cop establert per la crítica textual, diu:

C'est le plus souvent pour Saint-Marc que je partais, et avec d'autant plus de plaisir que, comme il fallait d'abord prendre une gondole pour s'y rendre, l'église ne se représentait pas à moi comme un simple monument, mais comme le terme d'un trajet sur l'eau marine et printanière, avec laquelle Saint-Marc faisait pour moi un tout indivisible et vivant. Nous entrions ma mère et moi dans le baptistère, foulant tous deux les mosaïques de marbre et de verre du pavage, ayant devant nous les larges arcades dont le temps a légèrement infléchi les surfaces évasées et rossés, ce qui donne à l'église, là où il à respecté la fraîcheur de ce coloris, l'air d'être construite dans une matière douce et malléable comme le cire des alvéoles. (Proust, 1989: 224)

El primer que crida l'atenció d'aquest passatge és que, si és a aquest moment al que remet la meditació del pati dels Guermantes, aquella rememoració, a banda de ser involuntària, és força imprecisa: no hi havia dues lloses desiguals al baptisteri de Sant Marc, sinó uns mosaics que, per la seva composició, donen al terra una certa irregularitat, i a les passes, inseguretat, alhora que es produeix una mena d'intensificació de la incertesa de les passes mateixes pel fet de saber que es fan sobre un terra com aquest; però, l'atenció de la mirada es troba desplaçada a les parets, per raons ben comprensibles. Aquesta imprecisió, tanmateix, no té perquè ser calculada ni, menys encara, negligent, perquè la memòria involuntària precisament atorga una prioritat al sentit de la rememoració per sobre de l'exactitud del record, que no necessàriament ha de ser rescatat en la seva completesa de detalls materials, la qual cosa, d'altra banda, seria impossible.

Però, el que no està tan clar és que el fet d'arribar a Sant Marc amb una gòndola pertanyi al mateix ordre de la condició narrativa de la memòria involuntària, encara que hi resulti determinant. En aquest punt, cal tenir present que el fragment restituït comença:

Après le déjeuner, quand je n'allais pas errer seul dans Venise, je montais me préparer dans ma chambre pour sortir avec ma mère, et pour prendre des cahiers où je prendrais des notes relatives à un travail que je faisais sur Ruskin. Au coup brusque que les coudes du mur (...) (Proust, 1989: 224)

És a dir, que ens trobem davant d'un dels múltiples passatges de la Recherche en què la tensió amb John Ruskin emergeix de manera sobtada, —un passatge que no hi era pas, en la publicació del capítol en la revista, l’any 1919:

Après le déjeuner, quand je n'allais pas errer seul dans Venise, je montais me préparer dans ma chambre pour sortir avec ma mère. Au coup brusque que les coudes du mur (...) (Proust, 1919: 8)

Però, a més a més, en aquest cas, la restitució -0 reconeixement- - de la presència de Ruskin es fa de forma tan explícita que ben bé podria dir-se que escenifica el mateix acte de preparar l'argumentació, la imminent discrepància amb l'autor de The Stones of Venice al qual, tanmateix, segueix i cita de manera subreptícia moltes vegades al llarg de la seva obra. 
Aquesta paradoxa és una constant en Proust, pràcticament des del primer moment que va llegir l'autor anglès, de qui va traduir i prologar La Bible d'Amiens, en 1904, i Sésame et les Lys: des trésors des rois, des jardins des reines, en 1906, que inclou l'extraordinari i fonamental prefaci «Journées de lecture», tota una teoria de la lectura com a reescriptura, en què el diàleg amb Ruskin esdevé tant ineludible com tens. Ja des d'aquells primers treballs es pot afirmar, com ha assenyalat Marie-Madeleine Martinet referint-se a la Recherche, que «les concepts ruskiniens sont devenus les thèmes imaginatifs et réflexifs proustiens. Les motifs ruskiniens, description d'une réalité extérieure, deviennent chez Proust des métaphores de la conscience réflexive et des sentiments» (Martinet, 1996: 220). I així és com, a partir de la distància que crea el discurs de Ruskin sobre Venècia, Proust pot plantejar-se una resurrecció o ressuscitació del passat d'ordre imaginatiu que permet una estètica que, de tant que s'acosta a la realitat i hi constata la seva fragmentarietat i discontinuïtat material i temporal, es distancia completament i definitiva del realisme que li servia de fonament narratiu, enfonsat per sempre més.

El paper de Ruskin per apreciar la Venècia proustiana és primordial; però no ho és menys per entendre com es relaciona Proust, en les pàgines de la Recherche, amb els autors que l'han resultat decisius. De fet, quan va publicar-se la traducció francesa del llibre de Ruskin, Les Pierres de Venise — que ell mateix, que ja havia traduït altres títols seus, s'havia proposat, però hi va haver de renunciar-, Proust no va estar-se d'afirmar que «la Venise agonisante de Barrès, la Venise carnavalesque et posthume de Régnier, la Venise insatiable d'amour de Mme. de Noailles, la Venise de Léon Daudet, de Jacques Vontade, exercent sur toute imagination bien née une fascination unique. Et, maintenant, de cette contemplation un peu passive de Venise, Ruskin va nous faire sortir. / Il nous permettra bien de glisser parfois en gondole» (Proust, 1971: 521). En aquell llibre, enmig de la seva innovadora reconsideració de l'arquitectura bizantina i dels seus elements més subtils, la fragmentació i el mosaic, Ruskin proposa un itinerari d'arribada a Sant Marc que atorga a la plaça una condició de necessitat per poder apreciar l'església en tota la seva magnitud, gràcies a la perspectiva de la plaça que emmarca la seva façana i la del Palau Ducal. L'alternativa proposada per Proust obvia la façana principal de Sant-Marc, bandeja la perspectiva emmarcada per les galeries porxades de les Procuratie, i ni esmenta el Campanile, perquè de fet l'itinerari plantejat a la Recherche pràcticament no permet ni veure'l. La prioritat narrativa és atorgada al baptisteri —al fet d'arribar-hi—, al qual s'accedeix, de fet, per una porta lateral, habitualment tancada o inadvertida.

Aquest itinerari permet l'arribada gairebé sobtada, accedir-hi directament sobre les pedres i incrustacions del mosaic, de manera que la concentració intensifica l'efecte que Proust vol produir en el lector: que hi ha una relació diferent i diferida amb aquella materialitat, i - la qual cosa no es comprendrà fins més tard - que la immaterialitat de la memòria involuntària permetrà copsar i comprendre com un «énigme de bonheur», (Proust, 1989: 446) que en el moment de trepitjar les incrustacions del terra no podia ser percebut. El pas de la navegació a l'encaminar implicaria, doncs, un canvi d'element que exerceix el paper de trànsit i de suspensió de la continuïtat dels fets, precisament per l'excepcionalitat del moment que, en la seva imminència, requereix aquesta mena d'aïllament discursiu; un aïllament del qual només s'explicita un primer sentit mentre un altre, essencial, queda ajornat de maner imperceptible. L'art analític i sintètic dels mosaics estudiat per Ruskin, és reconduït per Proust a un altre pla, en què la dependència dels arguments del britànic ja no resulta directa, sinó que ha estat reescrita a través d'un desplaçament dels sentits amb què entren en 
relació: la vista és substituïda per Proust per un tacte en desequilibri. L'evidència, doncs, queda desplaçada.

És, d'altra banda, el mateix tipus de desplaçament de l'atenció que només unes pàgines abans de la irrupció en el baptisteri ha permès centrar l'atenció en les finestres de Venècia. Aquestes finestres gòtiques, posades en relleu pel mateix Ruskin, són assimilades en Proust a una única finestra ogival de l'hotel en què s'hostatjaven el narrador i la seva mare. En posar en relació la finestra de la seva habitació a casa de la tieta Léonie, de la rue de l'Oiseau, a Combray, atès que «l'équivalent à tout ça existait à cet hotel de Venise» (Proust, 1989: 204), en realitat calia estar a les escoltes de:

ces mots si particuliers, si éloquents, qui nous font reconnaître de loin la demeure où nous rentrons déjeuner, et plus tard restent dans notre souvenir comme un témoignage que pendant un certain temps cette demeure fut la nôtre; mais le soin de les dire était, à Venise, dévolu, non comme il était à Combray et comme il est un peu partout, aux choses plus simples, voire les plus laides, mais à l'ogive encore à demi arabe d'une façade qui est reproduite dans toutes les musées de moulages et tous les livres d'art illustrés, comme un des chefs-d'œuvre de l'architecture domestique au Moyen Age. (Proust, 1989: 204)

Durant les pàgines anteriors, Combray i Venècia havien establert una relació, a través dels matisos de la «vida quotidiana», que no era «menys real» a Venècia que a Combray, $\mathrm{i}$ que permeten al narrador fer-se seus, des del primer moment que posa un peu al carrer, els materials de la ciutat com a no aliens, com a essencialment no diferents, sinó anàlegs, dels que menaven la vida a Combray, perquè, «il peut y avoir de la beuté, aussi bien que dans les choses les plus humbles, dans les plus précieuses» (Proust, 1989: 202). Amb aquest lligam entre dues ciutats que esdevenen reals $\mathrm{i}$ imaginàries alhora en la memòria, la finestra de l'hotel pot deixar de ser un monument memorable per a ser recordada per tot allò que no és la seva bellesa material, sinó la humil relació amb una mirada del passat: la imatge de la seva mare llegint en aquella finestra mentre l'esperava, imatge que el narrador va veure en arribar:

\begin{abstract}
de loin, et quand j'avais à peine dépassé Saint-Georges-le-Majeur, j'apercevais cette ogive qui m'avait vu, et l'élan de ses arcs brisés ajoutait à son sourire de bienvenue la distinction d'un regard plus élevé et presque incompris. (...) cette fenêtre a pris dans ma mémoire la douceur des choses qui eurent en même temps que nous, à côté de nous, leur part dans une certaine heure qui sonnait, la même pour nous et pour elles; et, si pleins de formes admirables que soient ses meneaux, cette fenêtre illustre garde pour moi l'aspect intime d'un homme de génie avec qui nous aurons passé un mois dans une même villégiature, qui y aurait contracté avec nous quelque amitié, et si depuis, chaque fois que je vis le moulage de cette fenêtre dans un musée, je suis obligé de retenir mes larmes, c'est tout simplement parce qu'elle me dit la chose qui peut le plus me toucher: «Je me rappelle très bien votre mère». (Proust, 1989: 204-205)
\end{abstract}

Aquesta manera de dipositar en els objectes un llenguatge secret, unes paraules que contenen el que encara no pot dir-se el narrador, però que està a punt de fer-ho sense adonar-se, parteixen no solament de la idea de mosaic i de fragmentarietat, o el valor històric i simbòlic atorgat a la finestra que Proust podia haver entrevist a la Venècia de Ruskin, sinó sobretot, o més aviat, fonamentalment, d'unes altres lectures. Una, que no té a veure amb Venècia, seria el tracte amb els objectes i amb els llibres après en el Voyage autor de ma chambre de Xavier de Maistre, (Martí Monterde, 2006; Sangsue, 1987: 164-194) que pel que fa al somieig inclou també una lectura explícita de Proust: Gérard de Nerval. L'altra, que incideix en la intensificació de la relació amb la immaterialitat de les coses materials, sí té a veure 
directament amb Venècia, i són els esbossos i contes venecians de Henri de Régnier. Ara bé: cal entendre com ha operat l'estratègia d'esborrament de les fonts en el cas de Ruskin, incloent-hi tant les al-lusions com les refutacions tàcites, el desenvolupament de les possibilitats no acomplertes per Ruskin que, per Proust, esdevenen incitacions, precisament per comprendre millor la seva relació amb altres autors importants en el desenvolupament de l'escriptura de Proust. És la memòria de la literatura, segons la formulació d'Antoine Compagnon (2009: 11) entesa com una mena de «voie moyenne entre la tradition et la intertextualité, entre la convention et la désorientation»(Compagnon, 2009: 21); literatura en moviment, que permet que la memòria involuntària sorgeixi del mateix text en què és, en el fons, reescrita. Així, seguint els arguments del mateix Proust sobre les reminiscències anticipades, el mateix Compagnon (2009:25) subratlla com els autors que Proust esmenta, al-ludeix o interpola, no implica que els faci servir de guies, i menys encara que el lector pugui fer-ho. El reconeixement de la literatura en la literatura, doncs, treballa d'una altra manera, que la relació entre Régnier i Proust permet aclarir.

\section{La memòria somiada: Henri de Régnier}

Per tal d'apreciar la importància de Régnier per a la concepció de la Recherche no deu considerar-se casual que, poques ratlles després de la meditació sobre la finestra, siguin esmentats els «magnífics estudis de Maxime Dethomas». Proust es refereix, en primer terme, als dibuixos amb què la revista Feuillets d'art va il-lustrar, en 1919, un escrit seu, «À Venise» - que al capdavall és una primera versió del capítol que ens ocupa. Aquells dibuixos tenien com a precedent els subtils aiguaforts i gravats que il·lustraven la primera edició dels Esquisses vénitiennes de Régnier, de 1906. L'al·lusió, estratificadament metal·lèptica, és tan evident com complexa, ja que remet tant a l'autor de la Recherche, a la primera publicació del fragment on s'insereix l'al·lusió, i a la seva relació amb l'autor dels Esquisses.

En aquells anys diverses revistes van acollir força escrits venecians de Régnier, l'obra del qual va merèixer ben aviat l'atenció del novel·lista; sens dubte, el dandysme i decadentisme de molts relats de Régnier hi tenia força a veure, però de seguida es pot apreciar que el seu interès anava encaminat a d'altres textures de la seva obra. Des que en el número de novembre de 1892 de la revista Le Banquet va ressenyar un llibre seu de poemes, Tel qu'on songe, Proust semblava tenir clara la importància de l'escriptura de Régnier: «Au dessús de ce qu'on appelle généralement intelligence, les philosophes cherchent à saisir une raison supérieure une et infinie comme le sentiment, à la fois objet et instrument de leurs méditations. C'est un peu de cette raison, de ce sentiment mystérieux et profond des choses que $\mathrm{Tel}$ qu'on songe réalise ou pressent» (Proust, 1971: 355). El fet que en l'edició original en la revista aparegués una errata — «présente» per «préssent»— que es perpetua en l'edició de 1927 de Chroniques, sembla que va disgustar a l'autor, que va maldar perquè es restituís el terme que ell volia i necessitava emprar, i que dóna la mesura de la importància de Régnier en la seva poètica posterior. (Proust, 1971:880n) Units ja per una certa amistat de caràcter salonnière - Proust havia conegut abans la dona de Régnier que a ell mateix-, en 1909 va realitzar un dels seus pastiches a la manera de Régnier, i va donar suport a la candidatura com a membre de l'Académie (Lesage, 1953). Finalment cal assenyalar que, quan comença a plantejar-se la redacció de la Recherche encara sense saber-ho, en Contre Sainte-Beuve, ja té força clar que la manera com Régnier s'acosta a les coses resulta, si més no, especial: «Pour Régnier, les choses ont le visage de nos songes» (Proust, 1971: 305). En 1912 apareix un altre recull seu, sota el títol Venise, en aquest cas il·lustrat per Henri Paillard, que cal 
considerar clau, si tenim en compte els relats que inclou. Tots aquells escrits, relats i esbossos aniran a fornir més tard els Esquisses vénitiennes que l'any 1920 — dos anys abans de la mort de Proust - recolliran una part important dels escrits de Régnier que va poder llegir durant els darrers anys de redacció de la Recherche.

Però, les consideracions proustianes sobre Régnier i Venècia no poden limitar-se a una qüestió temàtica, ${ }^{2}$ ni poden referir-se únicament a la semblança laberíntica, entre les passejades nocturnes de Marcel a Venècia i les caminades de molts dels relats de Régnier. Cal buscar un detall que lligui aquesta mena de somieig amb la immaterialitat material de la memòria involuntària. El recull de 1912 resulta determinant, ja que incloïa dos relats decisius per Proust: un titulat, senzillament, «Au cafè Quadri»; l’altre, «L'Encrier rouge».

\section{«Au cafè Quadri»}

Aquest conte va aparèixer per primera vegada en una publicació que també freqüentava Proust com a lector i com a autor: Le Figaro, en 1904, amb il·lustracions de Franc Lamy; narra un encontre en la terrassa d'un dels locals més antics de la plaça de Sant Marc —el Quadri, fundat en 1720 - un cafè que segurament no resulta tan afortunat en la història de la literatura com el Florian, igualment evocat per multitud de pàgines de Régnier, entre d'altres coses perquè el desnivell de la plaça fa que l'acqua alta el faci més sovint inaccessible, val a dir negat. Però, aquest relat només podia ubicar-se al Quadri, concretament a la seva terrassa, fora de la galeria porticada, en plena plaça, precisament per poder mostrar una veduta condemnada a la pèrdua.

La matinada del 14 de juliol de 1902 el Campanile de la Plaça de Sant Marc va ensorrarse de manera tan sobtada i sorollosa com elegant: sense causar cap desgràcia personal. Al cap de poca estona, la multitud que va reunir-se a la plaça només va trobar, davant del Palau Ducal, un munt de runa més aviat sorrenca. L'exclamació dov'era e com'era! va convertirse ràpidament en el lema d'una imperativa reconstrucció. (Boscolo Bielo, 2012) Ara tot just acaba de celebrar-se el centenari de la torre que pràcticament ningú no sap que data, només, de 1912. El simulacre perfecte, pràcticament sense testimoniatge d'haver-se produït, fa invisible la discontinuïtat temporal i material de la torre i la resta de la plaça, no perquè aquesta fos construïda tota alhora — que no va ser així-, sinó perquè el conjunt, tret de la torre, està unificat per una temporalitat successiva, no recomençada o duplicada. Dit d'una altra manera: podem imaginar-nos la plaça de Sant Marc sense aquesta torre? Mentre tothom pensa que la torre és l'original, i és admirada com a tal milions de vegades cada any, hem d'aturar-nos un instant a pensar com seria la perspectiva sense aquesta torre, una perspectiva que ha estat enfonsada en l'oblit. Les quatre fotografies mal comptades que existeixen de la plaça sense la torre poden fer ben poc contra els milions que la inclouen, i contra totes les vedute anteriors que les exigien. De fet, de les poques imatges que existeixen de la plaça sense el Campanile dues són, precisament, degudes a aquest relat: la il·lustració de Lamy per la primera pàgina en l'edició de Le Figaro illustré, en 1904, i una altra, encara més

\footnotetext{
${ }^{2}$ Segurament, la resistència a la tematització del tractament de Venècia en Proust explica per què en el primer congrés de 1'Association Internationale de Littérature Comparée, celebrat precisament a Venècia del 25 al 30 de setembre de 1955 sota el títol Venezia nelle letterature moderne, cap de les ponències presentades -d'inequívoca orientació tematològica-s'ocupa de Marcel Proust.
} 
excepcional, de Paillard, en l'edició de 1912, i que representa el moment precís de l'ensorrament de la torre. El gest narratiu de Régnier implica que no només hem de poder imaginar-la, la plaça de Sant Marc sense la torre, sinó que resulta necessari recordar-la així, ja que és un gest que no salva un indret o un objecte de la desaparició, perquè salva una altra cosa, la desaparició mateixa, de l'oblit que implica la reconstrucció.

A més a més, el relat des del Cafè Quadri resulta determinant precisament perquè narra una meditació dialogada sobre la caiguda de la torre, i la perspectiva sobre l'experiència personal dels espais, que la seva absència fa possible:

[Un venedor ambulant ofereix postals] J'en choisis une. Elle représentait le Campanile. Mes yeux allèrent vers l'enclos de planches qui entourait l'endroit où s'élevait auparavant la noble tour. Il reprit :

-Dire qu'il y a des gens pour prétendre que c'est mieux ainsi! Tenez, mon cher, il paraît même que nous sommes au meilleur point de vue pour juger de l'amélioration! J'ai entendu cela à la table d'à côté --des Vénitiens-- hier, car je viens ici tous les jours. J'y passe la journée. (Régnier, 1912: 122)

A continuació, el personatge explica la història del primer petó amb la seva estimada, fet al capdamunt de la torre, i de com, de retorn a París, en el moment de llegir a la premsa la noticia de l'ensorrament del campanile, va encaminar-se corrents cap al seu hotel, tot presagiant una tragèdia que, efectivament, s'havia consumat:

\begin{abstract}
»Dès que j'ai pu me traîner, je suis venu à Venise. J'ai choisi cette table. Il faut bien que je m'assoie ; je ne peux pas me tenir debout longtemps. La tête me tourne aisément. Alors je m'installe sur cette chaise et je regarde. Peu à peu, il me semble voir le Campanile sortir de cet enclos de planches ; il se reconstruit dans ma pensée et devant mes yeux. Il grandit, il monte, robuste, hautain et pourpré. L'Ange d'or ouvre de nouveau ses ailes au sommet. Alors, je retrouve la joie éprouvée là, jadis ; je la revis, je m'en enivre ; puis la vieille tour rouge oscille sous mes pieds. L'Ange d'or se précipite en bas, les ailes fermées. Tout s'écroule et s'effondre sous moi, et je m'abîme en mon malheur et mon désespoir. Alors je compare, je réfléchis, je délibère. Vivre ou mourir? (Régnier, 1912: 138)
\end{abstract}

El relat acaba d'una manera el·líptica que deixa obertes les possibles respostes a aquesta disjuntiva. Però el més rellevant per considerar la seva empremta en Proust és tenir present com el Campanile ressorgeix imaginàriament de la seva destrucció per reconstruir, ni que sigui de manera inaprehensible, aquell instant de felicitat, que torna a desaparèixer amb la consciència que la torre ja no existeix, que el lloc on va ser estimat, com l'amor mateix, ja no hi és, que cap acurada rèplica el substituirà, i que només una certa embriaguesa de la memòria permet acaronar-lo, sense esperança, gràcies a una taula de la terrassa del Cafè Quadri des de la qual es pot veure un munt de runa a partir del qual s'alça el polsim de la reminiscència.

El narrador torna, dies més tard, a Venècia; des del vaixell observa l'horitzó de la plaça, sense torre, i s'encamina cap al Quadri. El seu amic no hi és. Res no sabem del seu destí; però hem comprès que l'ensorrament del Campanile creava sentit, tant com la seva presència - i, un cop llegit aquest text, ja no la seva reconstrucció. La veritable torre és la torre perduda. I de la mà de Régnier hem pogut relacionar-nos amb el sentit d'aquella pèrdua, amb una perspectiva que potser mai més tornarà a ser materialment possible. Aquest relat de Régnier ens obliga, doncs, a relacionar la memòria no amb el lloc desaparegut, sinó només amb la desaparició.

\title{
«L'encrier rouge»
}

Inclòs també a Vénise, «L'encrier rouge» és l'altre relat que pot considerar-se determinant per la idea proustiana. Publicat originàriament a la revista L'Illustration, pel Nadal de 
1907 -amb il·lustracions de Vignal i de Giraldon, situa al narrador alhora en dos llocs i dos temps per construir una única significació, que esdevé ensems a Venècia i París, d'una manera semblant a com farà Proust en narrar alhora Venècia i Combray.

La semblança més evident entre el relat proustià i el de Régnier és que aquest inclou una passejada nocturna, onírica, que resulta comparable a la que es desenvolupa en Albertine disparue. En el relat de Régnier, aquesta passejada és múltiple i fragmentària: en primer terme és realitzada en un instant de lliurament a l'evocació imaginària: «Il me semblait, à mesure que nous approchions, que c'était mon souvenir qui te construisait à mes yeux» (Régnier, 1912: 18), fins el punt que un cop la ciutat compareix davant seu, no pot sinó expressar la «peur que tu ne fusses que l'image de mon illusion, évoquée là par la force de mon désir, et dont la féerie, détruite au moindre choc, ne laisserait plus d'elle, au-dessus du miroir fendu de la lagune, que la vapeur vaine d'un nuage irisé» (Régnier, 1912: 18). Aquesta transformació del desig, en el cas de Régnier té a veure amb el passat que es vol recuperar, i que condueix a una segona passejada que serà considerada com un somieig pel narrador.

\begin{abstract}
Et te voici devant moi, de nouveau, ce soir! Comme tu es silencieuse, maintenant! (...). Mon pied foule la dalle. Je marche au hasard, et pourtant je sais très bien où je vais. Je refais une des promenades faites si souvent. Ah ! voilà le palais Aldramin, le canal luisant s'esquive sous un pont courbe que je traverse. Je m'accoude, un instant, au parapet. Plus loin, il y a un «campo» solitaire. Il est entouré de vieilles façades jaunes et décrépites. L'une d'elles a été riche jadis. On y voit encore incrustés des disques de serpentin. J'aime ce puits à la margelle usée, et ce mur rouge que festonne une glycine, et au-dessus duquel pointe un cyprès. On respire une odeur de feuilles et de roses. Le nez en l'air, j'ai failli tomber en glissant sur une pelure de citron. Je ralentis le pas pour examiner ce balcon bombé où sèchent des linges à une ficelle et d'où pend une cage sans oiseau. Et cette curieuse porte avec ses marches rongées, ses colonnettes torses et son blason effrité! Voici une église. On y pénètre par un cloître où, dans un parterre humide, fleurissent des sauges. La nef est sombre. Au mur, des fresques indistinctes. Les clefs du sacristain tintent... (...) J'ai visité un grand palais. On m'a fait parcourir de vastes salles aux plafonds peints et dorés. Des lustres de Murano, compliqués et délicats, pendent à des tresses de verre. Dans un cadre d'or s'étale l'ample robe rouge d'un sénateur à grosse perruque poudrée. Le pavimento de mosaïque fléchit par endroits. Les pilotis doivent être bien vermoulus! A la porte d'eau, les «pali» sont plantés de travers. Leurs couleurs sont déteintes... Mais je crois que je me suis égaré. Vraiment, quel pauvre quartier! (Régnier, 1912: 19-20)
\end{abstract}

Com es pot apreciar, no és la Venècia carnavalesca la que es troba en aquest fragment; tampoc la més reconeixible o monumental; sinó una de secreta, oculta en la seva humilitat com el propi record des d'on emergeix. Són força evidents les textures d'aquest paràgraf que es poden trobar al desenllaç de la Recherche, especialment pel que fa als dubtes en les passes, la sensació d'estar caminant per un paviment incert en què cal una altra mena d'atenció. De fet, aquesta caminada s'interromp - en el moment de seure al Florian — quan el narrador esdevé conscient de la seva manera de lliurar-se al fet que, a aquesta Venècia havia sorgit de la pròpia imaginació, amb al·lusió inclosa a Xavier de Maistre que indica la memòria literària del text: «Ouf! je suis las. J'ai marché longtemps de long en large dans ma chambre. Si je m'allongeais sur mon divan?» (Régnier, 1912: 22). Però, tot seguit, el divan esdevé una gòndola que llisca silenciosa pels canals; però, just en el moment en què es considera que tot plegat ha estat el record d'un somni, aquest torna a interrompre's com a somni d'un record: «Je crois que je viens de dormir pour de bon, d'un sommeil bizarre, d'où je me réveille tout étourdi et l'oreille tintante» (Régnier, 1912: 23). Aquest soroll és el del timbre, que sona a casa seva, a París. I aleshores s'hi presenta un negre que el lliura una carta, el commina a vestir-se de carnaval i seguir-lo. En passar el llindar de la casa, les 
voreres de la ciutat experimenten una sorprenent transformació que fa que les passes esdevinguin desplaçades, primer, i finalment insegures:

voilà qui est de plus en plus étrange. Au ras du trottoir, l'eau miroite et clapote, il y a une gondole arrêtée. Mon nègre m'y fait monter. Il pose son fanal et prend la rame. La gondole vire doucement. Devant elle, il n'y a plus qu'une étendue d'eau obscure. Je me retourne, ma maison n'est plus là. Autour de nous, s'étale la lagune. Paris a disparu. Plus rien. Un silence extraordinaire. Le gondolier rame vigoureusement. Nous allons vite. Parfois, il s'essuie le front. Le temps passe. Nous avançons toujours. Enfin, quelque chose de vague se dessine sur le ciel nocturne. Une rive plate apparaît. Je distingue le campanile d'une église. Nous approchons. Tout à coup, la gondole s'arrête. Le nègre saute à terre. Je l'imite. Mes pieds s'enfoncent dans un sol spongieux qui se raffermit peu à peu. (Régnier, 1912: 24)

Com ja havia advertit Proust, el somni en Régnier adquireix una categoria narrativa, poètica, sense la qual no s'entén la seva manera de mirar Venècia, de manera que — més enllà del record, més enllà del somieig, el narrador, en el seu darrer encaminar del qual no desperta- les estàtues del cavall i del lleó de la plaça de Sant Marc apareixen dotades del moviment de quan no eren estàtues, sinó el moment fundacional de la «cité marine» (Régnier, 1912: 27), observada com l'origen d'un desig en la seva escena primigènia: «je m'agenouille devant Venise naissante, dont un peuple d'ombres célèbre aujourd'hui, en une fête de silence et de rêve, la nocturne Épiphanie!» (Régnier, 1912: 28).

Són aquests els fragments que porten a pensar en les caminades nocturnes de Marcel, unes caminades en què «Il était bien rare que je ne découvrisse pas au hasard de mes promenades quelque place inconnue et spacieuse dont aucun guide, aucun voyageur ne m'avait parlé» (Proust, 1989: 229). Per més que sigui recurrent la referència als laberints de carrers, carrerons i petits canals i ponts en qualsevol dels autors que hi han dedicat algunes pàgines a Venècia, molts dels quals Proust havia llegit amb atenció, com s'ha vist, la seva narració en aquest punt no és una mera descripció impressionista, sinó que integra plenament la meditació sobre la pròpia poètica, en allò que té a veure amb la manera de narrar de Régnier:

\begin{abstract}
Je m'étais engagé dans un réseau de petites ruelles, de calli. (...) ces calli divisaient en tous sens, de leurs rainures, le morceau de Venise découpé entre un canal et la lagune, comme s'il avait cristallisé suivant ces formes innombrables, ténues et minutieuses. Tout à coup, au bout d'une de ces petites rues, il semble que dans la matière cristallisée se soit produite une distension. Un vaste et somptueux campo à qui je n'eusse assurément pas, dans ce réseau de petites rues, pu deviner cette importance, ni même trouver une place, s'étendait devant moi entouré de charmants palais, pâle de clair de lune. (...) Ici, il semblait exprès caché dans un entrecroisement de ruelles, comme ces palais des contes orientaux où on mène la nuit un personnage qui, ramené chez lui avant le jour, ne doit pas pouvoir retrouver la demeure magique où il finit par croire qu'il n'est allé qu'en rêve. (Proust, 1989: 229-230)
\end{abstract}

De fet, aquesta distensió, aquesta mena de moviment incessant de la ciutat sobre ella mateixa, pren el seu sentit definitiu en la impossibilitat de recuperar-la. Tot buscant la seva plaça perduda, el narrador fracassa perquè es tracta d'una pèrdua que es produeix precisament perquè el recorregut diürn és incapaç de repetir els itineraris nocturns, per més que transiti pels mateixos carrers i places, per més que repeteixi mecànicament les mateixes passes:

Le lendemain je partais à la recherche de ma belle place nocturne, je suivais des calli qui se ressemblaient toutes et se refusaient à me donner le moindre renseignement, sauf pour m'égarer mieux. Parfois un vague indice que je croyais reconnaître me faisait supposer que j'allais voir apparaître, dans sa claustration, sa solitude et son silence, la belle place exilée. À ce moment, quelque mauvais génie qui avait pris l'apparence d'une nouvelle calle me faisait rebrousser chemin malgré moi, et je me trouvais 
brusquement ramené au Grand Canal. Et comme il n'y a pas, entre le souvenir d'un rêve et le souvenir d'une réalité, de grandes différences, je finissais par me demander si ce n'était pas pendant mon sommeil que s'était produit, dans un sombre morceau de cristallisation vénitienne, cet étrange flottement qui offrait une vaste place entourée de palais romantiques à la méditation prolongée du clair de lune. (Proust, 1989: 230)

La plaça, la veritable plaça perduda, és la somiada — o que es creu somiada_-, la caminada en la nit, impossible de recobrar. Una plaça exiliada descrita en una mena de llengua estrangera, que es fa tan fonedissa com allò que descriu. I, en la tradició proustiana, és com si el narrador hagués tornat a somiar el somni de Régnier per tal de desenvolupar aquesta part del seu relat.

Però no és en el fet del passeig nocturn a la recerca de la plaça perduda on es troba el punt més important d'afinitat amb Régnier mostrat per Proust en aquest punt: la pèrdua mateixa de l'indret introbable fa que la plaça exiliada i la torre ensorrada de Régnier pertanyin al mateix plec de memòria, que només ha pogut ser entrevist en la narració desplegada amb un passeig al llindar del somni o del record, com la Venècia originària dels fundadors.

Ara bé: encara que aquests siguin els passatges més clarament relacionables amb la mirada a Venècia de Proust, són les primeres pàgines del relat de Régnier, les que encara no es desenvolupen a Venècia, les més importants per la poètica de la memòria involuntària. Aquelles primeres pàgines dediquen una atenció absolutament desmesurada a un gest de contemplació d'un objecte, el tinter que el narrador té a la taula, mentre s'espera el moment de posar-se a escriure; fent voltes i més voltes a la mirada de l'escriptori, aconsegueix una dilació que fa pensar en la del narrador proustià estès al llit sense arribar-li la son. El començament d'aquest relat no deixa de ser una meditació sobre la mateixa activitat d'escriure, la seva litúrgia i els estris que li són propis, i sobre com no és possible desfermar-la de manera arbitrària, sinó que ha d'esperar a què es produeixi com a esdeveniment impensat:

Souvent, comme aujourd'hui, après quelque dure séance de travail où ma main a fait des centaines de fois le trajet de la page à l'encrier, lorsque je sens mes doigts se crisper et mon bras s'alourdir, je m'arrête, et je m'amuse à considérer en rêvassant l'outillage familier qui est devant moi. La lampe l'éclaire de sa lueur. Il est tard. L'encre miroite en son double puits de cuivre. Hélas! me dis-je en soupirant, parviendrai-je jamais à faire sortir de leur liquide obscurité l'Idée qui s'y cache comme une sombre ondine? Ah! que je voudrais voir ses pieds nus danser sur le papier, et y laisser la trace écrite de leurs pas! (Régnier, 1912: 8-9)

En aquests instants d'indeterminació, el narrador repara en una petita campaneta que completa el joc del tinter, a la qual, en un primer moment, no se l'atorga una excessiva importància: «Quelque chose m'y attire encore! Ah! oui, c'est cette petite sonnette qui complète comiquement son attirail, tel qu'on le vendait aux gens, en quelque boutique du Rialto ou de la Merceria de Venise!» (Régnier, 1912: 10). De què serviria agitar-la? Es pregunta el narrador, tot conscient que entre el món que la va crear i el que l'acull en el seu escriptori hi ha un abisme. Aleshores sent com una mena de crida silenciosa, de la qual, tanmateix, no fa gaire cas: «Il y a des moments où nous comprenons l'esprit des choses, où nous consentons volontiers à leurs humbles désirs. Pauvre clochette, comme sa voix doit être faible et vieillotte! Comme sa chanson doit être aigrelette et lointaine! J'en ris d'avance» (Régnier, 1912: 12). Però, en el moment en què la pren, cedeix desinteressadament a la crida que ell mateix ha creat per a aquest objecte amb la seva atenció desmesurada, i que en principi no era més que un subterfugi per eludir les penalitats d'una tasca com la d'escriure, sotmesa al que anomena «ansietats indefinibles», en el moment en què una onomatopeia — «Ding!!!»— omple la pàgina: 


\begin{abstract}
Un seul coup a tinté, bref. J'écoute. Au lieu de s'affaiblir et de s'éteindre, il vibre finement, longuement, obstinément. Le son rôde dans l'air comme une abeille de son sortie de la minuscule ruche de cuivre jaune. Il rôde. Soudain, il m'entre dans l'oreille et pénètre dans ma tête. Là, au lieu de se poser, il tournoie, il vire, il bourdonne. Il grandit, s'enfle, s'augmente. Il résonne singulièrement ; il s'amplifie avec douceur, avec force. Il est allé éveiller quelque chose qui dormait au fond de ma mémoire. Il y ranime des échos engourdis. Entre eux, ils s'appellent, se répondent, se mêlent, s'unissent en une harmonie grave et lointaine. Ils m'emplissent, débordent, m'environnent. Toute la chambre est comble de leur rumeur. Et je la reconnais, cette rumeur qu'a suscitée en moi le branle de la petite clochette, et voici que, les yeux fermés, le coeur ému, je m'abandonne à son sonore enchantement. (Régnier, 1912: 13-14)
\end{abstract}

L'amplificació narrativa resulta tan evident que fins i tot pot arribar a exasperar el lector, la qual cosa no deixa de ser un efecte previst pel text, que va elaborant minuciosament aquest instant d'encantament. Venècia no reapareix perquè sempre hi hagi estat present: en cap moment s'obvia que el tinter era un souvenir de Venècia; el que s'esdevé en posar la campaneta en moviment restitueix la idea de souvenir a la seva essència, el seu esperit, traspassant la seva materialitat quotidiana que el cosificava en ornament, o en estri. La manera com el ressò cedeix el pas de manera tan ferma com paulatina, indeturable, als ressons, als echos, produeix el desbordament i el desplaçament cap a l'altre indret del relat, que emergeix d'aquesta remor que acaba per saturar l'espai narratiu tant com la consciència del narrador. Un narrador que, en afirmar que aquest so ha anat a despertar alguna cosa dormida al fons de la seva memòria, ja sap que no podrà dominar-los, ni a la memòria mateixa ni als sons que l'han posada en moviment.

\footnotetext{
Et je vous reconnais, cloches délicieuses et diverses, cloches de Venise, cloches de bronze, d'or et de cristal que j'ai tant de fois entendues; vous qui, du haut des campaniles, retentissez chaque jour dans l'air marin et dont les voix descendent sur les «campi» déserts, chantent au tournant des «calli» étroites, se répercutent à l'angle de «rii», ô vous, cloches vénitiennes, cloches de San Marco et de la Salute, cloches des Frari et de San Giovanni e Paolo, cloches des Gesuati et de San Sebastiano, et vous, cloches de San Giorgio Maggiore et de la Giudecca, cloches des îles de la lagune, vous qu'a ramenées jusqu'à moi votre soeurette minuscule, car c'est elle qui est allée vous chercher là-bas et qui vous a conduites ici pour que nous retournions ensemble vers la Ville divine que vous couronnez de votre guirlande sonore, vers cette Venise que voici encore une fois apparue en ma pensée, debout en sa grâce souveraine, en son manteau de lumière que nouent les mille rubans de ses canaux, et chaussée des patins noir et or de ses gondoles recourbées! (Régnier, 1912: 14-15)
}

El pas de la formulació de Régnier: «Et je vous reconnais, (...) cloches de Venise», a la formulació proustiana: «Et presque tout de suite je la reconnus, c'était Venise» marca, com sol ser habitual em Proust, una lectura com a incitació que s'ha convertit en reescriptura que no esborra les seves empremtes, sinó que les inscriu de manera discreta, encriptada i indesxifrable alhora, a l'espera de ser, al seu torn, també reconegudes com una tradició invisible.

En aquest punt, la consideració de l'oblit resulta no menys important. En Proust en realitat no hi ha oblit de les pedres del baptisteri de San Marc; senzillament era un record que no se sabia que es tenia, i que es trobava al dessota d'un esdeveniment efectivament narrat; perquè, al capdavall, sí que havia estat enunciat com a passes sobre el mosaic, però sense saber que resultarien més determinants que la contemplació de les parets en aquell mateix moment, precisament pel desplaçament de l'atenció. Per això la manca de precisió en referir-s'hi no és pas aleatòria, sinó que té una clara funció narrativa. En canvi, una passa enrere de l'experiència proustiana però encaminant-se en la mateixa direcció, el narrador de Régnier explica com havia intentar oblidar Venècia a través de la llunyania, $i$ en canvi Venècia sempre reapareixia, de manera sobtada, en qualsevol racó del món, exigint el retorn; 
construint un desig que Proust mateix també inscriu durant totes les pàgines anteriors al capítol tercer d'Albertine disparue: el desig de Venècia com a forma d'un record que encara no es té, però que ja forma part de la imaginació de l'individu, i per tant de tot allò que és capaç de comprendre.

Per això és a Venècia que pot formular, el narrador proustià, que quan va morir la seva àvia no havia sentit gaire pena, però que en canvi, aquest sentiment el va envair molt més tard: «je n'avais souffert effectivement de sa meurt que quand des souvenirs involontaires l'avaient rendue vivante pour moi» (Proust, 1989: 220). La incapacitat per ressuscitar Albertine, de la mateixa manera, es devia a la incapacitat de ressuscitar-se a si mateix; «de ressuscitât mon moi d'alors» (Proust, 1989: 221). La constatació lancinant que, en definitiva, és el pas del temps el que permet afirmar: «Cela bouleverse parce que cel·la veut dire: l'homme que j'étais, le jeune home blond n'existe plus, je suis un autre» (Proust, 1989: 221). Però de la mateixa manera que és impossible el record, igualment impossible és l'oblit. Però, com parlar-ne, de l'oblit?.

En reprendre aquesta impossibilitat de l'oblit de Venècia en Régnier, Proust l'assumeix no com a fracàs, sinó condició de la memòria, que reapareix dominant el record i l'oblit voluntaris, i que fa que l'oblit pugui deixar-de ser-ho, però no per la reconstrucció, ni la recuperació, sinó pel ressorgiment, la reminiscència que, en lligar dos sentits —encerclats en objectes, indrets, fets - els fa significar. El so de la campaneta del tinter no fa sinó sintetitzar i aprofundir en aquesta consideració de la memòria, densificar-la en un objecte qualsevol, al qual basta atendre, escoltar, permetre que s'hi desfermi l'infinit que, fins aquell moment, romania velat, que esperava a la callada. Venècia sempre hi havia estat, continguda, en un so que calia fer sonar, amagada en la immobilitat quotidiana o instrumental d'un objecte, és a dir, en allò que l'impedia significar de la seva materialitat, i que en realitat contenia — també en el sentit de retenir, d'evitar el seu desbordament- l'immaterial.

De fet, alguns anys abans el mateix Régnier ja havia esbossat aquesta mateixa reflexió, també al voltant dels mateixos estris d'escriptura ja desapareguts de les nostres taules de treball —el tinter amb la campaneta per avisar_- en «l'Écritoire», un dels relats recollits en el volum de 1906 il·lustrat per Déthomas. De fet, si tenim present que el viatge real de Proust a Venècia s'havia produït en 1900, és molt possible que no calgui esperar a la seva inclusió en el volum de 1912 per pensar que va captar l'atenció de Proust: «Son plateau, peint d'un rouge vif, à la mode vénitienne d'autrefois, présente les deux encriers de cuivre, au couvercle surmonté d'un fruit ciselé. Devant eux la sébile offre le poudre à sécher. De chaque côté se dressent le plumier et la clochette pour avertir le petit laquais qui portera la lettre» (Régnier, 1906: 27). Al capdavall, «L'encrier rouge» també pot considerar-se'n una variació, o, més aviat, el desenvolupament d'una idea que potser quedava massa densa i explícita; però no solament pel que fa al tractament de l'objecte, sinó també pel que fa al tractament de la memòria, o, més aviat, del passat i de la manera de relacionar-s'hi a través del temps:

\footnotetext{
Mais je secoue bien inutilement ma clochette, et, fatigué, je la repose sur le plateau, peint en rouge vif, de l'écritoire de cuivre... Personne ne vient. Le petit battant de bronze ne fait pas assez de bruit à l'intérieur de sa tulipe renversée. Hélas! Il faudrait que son tintement traversât le temps, remontât l'espace de plus d'un siècle, pour arriver à l'oreille du passé. Fou que je suis, Jacinto et Geromino ne sont plus que des ombres vaines. Cependant les ombres entendent parfois les appels des vivants. Je le sais! (Régnier, 1906: 28-29)
} 
Sens dubte, malgrat el seu esquematisme, també aquestes ratlles de 1906 resulten importants per la manera de concebre l'escriptura en Proust. I, tanmateix, s'ha de reconèixer que, segurament sense proposar-s'ho, Régnier hi havia pressentit el gir que li donaria Proust a la lliçó que havia d'extreure de les seves pàgines.

\section{Conclusions}

Aquests passatges de l'obra de Régnier, aquesta manera de demorar-se en l'atenció a un objecte, o en la pèrdua d'un espai, per tal que més enllà de la seva insignificança acabi mostrant la seva significació en l'individu que l'observa, fins desfermar un viatge nocturn, somiat, a Venècia, un viatge que no té perquè realitzar-se per a construir el seu sentit, aquesta manera de relacionar-se amb Venècia, que cap presència duradora o cap rèplica fidel podria satisfer, obren el camí perquè la modèstia d'un objecte pugui contenir tota la forma secreta de la memòria i el llenguatge amb què aprehendre-la. Marcel Proust, en reescriure de manera gairebé imperceptible Régnier, no fa sinó incidir en una tradició que ell mateix construeix a través d'uns precursors que el seu relat desvela i vela alhora, la qual cosa implica una concepció de la lectura, i a diferència de les reescriptures temàtiques del viatge a Venècia, i per tant instrumentals $i$ tòpiques, es relaciona amb aquell ciutat no a través de les seves pedres, ni les seves aigües, sinó amb el seu sentit.

\section{Bibliografia citada}

AA.VV. (1975): «Proust et la Nouvelle Critique». Cahiers Marcel Proust, nouvelle série, no 7, «Études proustiennes II».

Boscolo Bielo, Marco (2012): Crollo e ricostruzione del Campanile di San Marco. Roma: ed. Legislazione Técnica.

Compagnon, Antoine (2009): Proust, la mémoire et la littérature: séminaire 2006-2007 au Collège de France. Paris: O. Jacob.

Compagnon, Antoine (2013): Proust, entre deux siècles. París: Seuil.

LAtTRE, Alain de la (1978): La doctrine de la réalité chez Proust. París: José Corti.

LeSAGE, Laurent (1953): «Proust and Henri de Régnier». Modern Language Notes vol 68, 1: 8-13.

MARTi Monterde, Antoni (2006) «Introcucció a Xavier de Maistre: Viatge a l'entorn de la meva cambra. trad. cat. de S. Company i A. Torcal». València: Publicacions de la Universitat de València.

MARTINET, Marie-Madelaine (1996): Le Voyage d'Italie dans les littératures européenes. París: Presses Universitaires de France.

MiLly, Jean (1994): «Faut-il changer la fin du roman de Proust?», Études françaises vol. 30, 1: $15-40$.

Milly, Jean (2000): «Proust et Henri de Régnier» modes proustiens de l'intertextualité». Revue d'Histoire littéraire de la France 1: 27-44.

Proust, Marcel (1987-1989): À la recherche du temps perdu. ed. de Jean-Yves Tadie, et. al. París: Gallimard (B. de la Pléiade) [Vol. I: 1987; Vol. II: 1988a; Vol. III: 1988b; Vol. IV: 1989].

Proust, Marcel (1971): Contre Sainte-Beuve. Pastiches et mélanges. Essais et articles, ed. de Pierre Clarac i Yves Sandre. París, Gallimard (B. de la Pléiade).

Proust, Marcel (1927) : Chroniques. París: Libr. Gallimard.

REGNIER, Henri de (1904): «Au Café Quadri», Le Figaro illustré, núm. ext. de juliol. 
REGNIER, Henri de (1906): Esquisses vénitiennes, París: Collection de l'Art Décoratif.

REGNIER, Henri de (1907): «Venise: L'encrier rouge», L'Illustration, n. 3380, 7 desembre.

REGNIER, Henri de (1912): Venise. L'Encrier rouge. Esquisses et Sonnets. Au café Quadri.

París: Société des amis des livres.

REGNIER, Henri de (1920): Esquisses vénitiennes. París: Mercure de France.

SAngsue, Daniel (1987): Le Récit excentrique. Gautier, De Maistre, Nerval, Nodier. París: Librairie José Corti.

YoshIDA, Jo (1987): «L'après-midi à Venise: autor de plusieurs textes inédits sur la basilique Saint-Marc». Cahiers Marcel Proust, 14, Études proustiennes VI: 167-189. 